Lanas \& Huuki (2017). Thinking beyond student resistances

Lanas, Maija \& Huuki, Tuija (2017). Thinking beyond student resistances: a difficult assemblage in teacher education. European Journal of Teacher Education. 40(4), 436446. DOI:10.1080/02619768.2017.1349094

\title{
Thinking beyond student resistance: A difficult assemblage in teacher education
}

\begin{abstract}
This paper draws on feminist new materialist, poststructuralist and post-human theories to rethink discomforting moments when engaging with sensitive topics in teacher education. It is argued that the common approach to such events-as instances of student resistance or pedagogical failures - is both simplistic and problematic, and that a more holistic and in-depth approach is needed. Inspired by Deleuze and Guattari's ideas of assemblage and affect, our aim here is to re-theorise an instance of such an event in an attempt to make visible how place, space, objects, emotion, affect and history entangle in predictable and unpredictable ways in teacher education. The aims of the paper are to propose new ways of engaging with discomfort in teacher education and, secondly, to introduce post-human approaches in the field of teacher education, where they are underrepresented.
\end{abstract}

Keywords: post-human, post-structuralism, teacher education, student resistance, emotion, affect, assemblage

Maija Lanas, Tuija Huuki, University of Oulu 
Lanas \& Huuki (2017). Thinking beyond student resistances

\section{Thinking beyond student resistance: A difficult assemblage in teacher education}

\section{Introduction}

I am early. I am here to deliver a talk about power and violence in peer relations in young peer cultures, entitled "What happens before bullying?" The topic is sensitive, but I feel comfortable with it. I have often lectured about this, and I have been studying power in people's peer relations for over a decade. The students start drifting in-mostly women, from several different faculties. All are studying to become subject teachers, which means that they already have a major subject-for example, mathematics, geography or history. We have had to reschedule the lecture a couple of times, and the course coordinator has told me that the students have been awaiting it eagerly. I have prepared thoroughly; it's looking good, and it starts off well. I'm lecturing about normalised and mundane forms of abuse of power in young people's peer cultures that escape the definitions of bullying and need to be addressed if we are to provide emotionally safe schools.

But then something happens, or some things happen. As I am lecturing, I feel tension and anxiety building up. Ifeel tension around me, in the lecture hall, in the students. The weirdly hushed silence that prevailed in the room from the first minute of the lecture turns into student fidgeting. They whisper and snigger; they give each other looks, and the tone of their questions is unsettling. I feel uncomfortable, unsafe and insecure: I don't come out from behind the booth, and I don't deviate from my lecture notes. Despite the fidgeting and whispers, the room is stagnant, pregnant-with what, I don't know. At the end of the lecture, four students stay to talk; one of them says he came in late and notes "It was so silent; it was weird. One could sense we're talking about serious matters here". According to the course director, "But what can we do, how can we stop this?" was the most common question among students after the lecture. I felt a complicated combination of 'bad', shaken and guilty. Pedagogically, the lecture felt like a failure, and this is how I reported it to my peers. Was it the students? Was the topic too much for them? Was it me? What should I have done differently? What happened?

What happened in the situation described above? Such situations are familiar, in one form 
or another, to many teacher educators who engage with sensitive societal topics such as violence, oppression, privilege, or cultural differences of gender and race — short or longer events or situations in which educator or students feel hurt by one another or by the situation. Why does it sometimes happen that instead of being joined by an affect (see Niccolini 2016), educator and students are separated from each other, and even from the content taught? Why does the situation described above change from an initial "eagerly awaited" to "dangerous" as it unravels?

In the field of teacher education, such discomforting instances have often been discussed in terms of student resistance, as pedagogical failures or as pedagogical opportunities, also reflected in the account of the lecturer above (Tuija, the second author of this paper). She is looking for something on which to pin the experience. In this paper, we argue that more holistic and in-depth elucidation of such events produces new knowledge about implicit forces at play in teacher education.

In discussing such events in terms of student resistance, that resistance may be viewed as driven by lack of knowledge (e.g. Bryant and Bates 2010); as directed at new theory (e.g. Barcan 2002), at new pedagogies (Blaise and Elsden-Clifton 2007) or at new skills (e.g. Holloway and Gouthro 2011); or at specific topics, such as privilege, oppression, feminism or special needs (Aveling 2002, 2006; Evans-Winters and Twyman Hoff 2011; Titus 2000; Williams and Evans-Winters 2005). Indeed, educators make ready use of the term student resistance without further attending to the power position from which that resistance is identified. As a consequence, there is a risk that discomfiting moments in teacher education are too often seen by teacher educators as a problem located in the students. In this regard, Barcan (2002) noted that the trope of student resistance “masks our own resistance to thinking more about why some students don't want to hear what we have to say". Segall (2008) drew attention to the conflicting goals of educators and students, suggesting that while educators may wish to trouble existing understandings, students' pressing concern is to gain confidence in teaching rather than to undermine their existing confidence. The problem here is that, in attributing the discomfort of the situation to the students and their resistance, we may seek to fix the problem by focusing on the students when we should instead be looking more carefully at the emerging emotions and the wider context in which they emerge.

In conceptualizing such situations in terms of resistance or focusing solely on pedagogical solutions, there is a risk of neglecting emotion and affect. Despite increasing 
Lanas \& Huuki (2017). Thinking beyond student resistances

attention to emotion in education and in teacher education, it often remains undertheorized and is seen solely in terms of learning outcomes. In general, emotions are recognised only to the extent that they support or hinder learning - that is, as either problems or solutions. Challenging this approach, emerging post-structural and posthuman scholarship proposes that affect and emotions may be pedagogical in their own right, especially in pursuit of social justice (Bronkhorst et al. 2014, 73-82; Niccolini 2016; Probyn 2004; Wang 2008, 10-16; Wang 2005, 45-60; Zembylas 2010, 253-270). For example, Zembylas (2010) suggested that feelings of discomfort should be engaged with in critical ways in order to see things differently and to transform underlying assumptions and beliefs. Niccolini $(2016,230)$ in turn argues that "rather than seeking to foreclose intensities in classrooms, educators might pay more attention to how affect offers richly generative, but often overlooked, sites of pedagogical force”. Similarly, Probyn (2004) emphasised that, in academic or educational contexts, some knowledges are essentially affective and emotional. In other words, emotion is not to be considered either a hindrance or a means to an end but as ingrained in the context and taught content.

This implies that some knowledge may be emotionally difficult (Britzman 1998) - for example, in requiring us to overcome our biases and to rethink the world, ourselves and others. At the same time, those same knowledges may not prove difficult in other contexts. As a material-discursive context, teacher education may prove particularly challenging in this regard. As we have suggested elsewhere (Lanas 2014, 2015), teacher education may not offer students the material or discursive spaces in which to engage in constructive ways with pain or difficult knowledge; discomforting events, then, may be less a question of student resistance to knowledge or pain than of students' efforts to make sense of pain and knowledge within the broader material-discursive frameworks within which they think and act.

Teacher education incorporates powerful discursive practices to which both students and teacher educators have become accustomed. These existing practices are likely to dominate the perceptual awareness of student teachers and of teacher educators, with implications for what can be said, seen, thought or even felt (Sumara, Davis, and Iftody 2008, 155-172, 170). For that reason, when looking at emotions in academic or educational contexts, we must also interrogate the broader material-discursive context in which particular knowledges come to be experienced as difficult, certain situations come 
to be experienced as discomforting, and such discomfort comes to be experienced as a problem in the first place.

The research reported here takes the lead from Zembylas, Niccolini, Wang, Barcan, Segall, Green and Reid, and Sumara and her colleagues, and explores the potential of discomfort in teacher education by taking an in-depth look at the discomforting event alluded to in the opening section. It builds on post-structural and post-humanist theories, engaging in particular with radical post-individual and nonanthropocentric theories that explore new ways of thinking about educational spaces and subjects as constituted through complex configurations of networks comprising heterogeneous components that include affectivities (Niccolini 2016; Probyn 2004; Strom 2015; Youdell and Armstrong 2011). This paper has two goals; the first of these is to contribute to the creation of new tools for thinking about these discomforting situations and new possibilities for educators who find themselves in such situations. The second goal is to introduce post-human approaches (Barad 2007; Deleuze and Guattari 1987; Grosz 2005, 2011) into the field of teacher education, where such approaches are relatively new.

In what follows, we will disentangle the dynamics at play in the event in terms of material and discursive elements (discussed as "flows of forces" in new materialist and post-human theories) that conflict with or contradict each other, so explaining the discomfort caused when simultaneously present. By disentangling these dynamics, we will argue that teacher education is not simply a matter of pedagogical questions, content knowledge or students' skills; rather, there are multiple unmanageable and unprecedented forces at work that emerge within specific material and discursive configurations of power relations, referred to by Deleuze and Guattari (1987) as "assemblages". We conclude by suggesting that the central pedagogical question in teacher education is not how discomfort or pain can be excluded but how pain can be rendered a "safe-enough" element of the pedagogical process. We begin by defining the central concepts of assemblage and affect and what they bring to the discussion of teacher education.

\section{Mapping forces, assemblages and affects in a pedagogical event}

In disentangling the dynamics of the event described earlier, we have drawn on new feminist materialist and post-human theories that propose post-individual, nonanthropocentric and non-dichotomous understandings of nature-culture interactions 
(Alaimo and Hekman 2008; Barad 2007; Manning 2013). This approach shifts the locus of education from bodies and individuals towards the web of forces, intensities and encounters (Braidotti 2006, 41) that produces agency, bodily capacities and events. Deleuze and Guattari (1987) called these configurations of relations "assemblages", in which individuals, groups, societies and institutions are understood as dynamic heterogeneous amalgams of human and non-human elements, with forces-for example corporeal, technological, mechanical, virtual, discursive, historical and imaginary - that pull in many directions at once. Self, agency and the apparent reality of relations emerge in these assemblages.

Considered as an assemblage, a lecture is an amalgam of material elements (e.g. large lecture hall, outside own faculty; podium, PowerPoint and screen; how the audience seating towered diagonally above the lecturer; students' phones or tablets); the setting (e.g. delayed lecture; students' expectations; previous lectures within the same course; timing of lecture in relation to lunch); memories and experiences (e.g. bullying in personal histories; previous lectures about linking topics); discourses (e.g. norms in teacher education); physiological processes (e.g. fidgeting; anxiety; physical proximity to other students; physical reactions to emotional stimuli); personal and cultural contexts (e.g. cultural backgrounds, major studies); policies (e.g. credits to be accumulated during the semester) and myriad other fragments that vibrate in the event.

To view the described event as an assemblage is also to acknowledge that it is, like any assemblage, a transient agential cut (Barad 2007), arrested for inspection and discussion; there is always more to any assemblage than is discussed. For example, beyond the lecture itself, teacher education as a whole can be seen as an assemblage from which the individual lecture is cut; in discussing teacher education, we are not dealing with a simple top-down process, in which knowledge and perspectives are transmitted from formal institution to students, but with a multi-layered process, in which student teachers engage with multiple directions. As student teachers are exposed to new theories or perspectives, they view these through sedimented systems of knowledge and beliefs about teaching and being a teacher (Cochran-Smith 2003; Furlong 2013; Green and Reid 2008; Lenz Taguchi 2007; Phillips 2010). Like any assemblage, teacher education also extends beyond a particular time and place; student teachers have more than a decade of previous personal experiences with their own teachers, embodying historically produced lay theories, culturally embedded archetypes of teaching (Furlong 2013), memories and 
Lanas \& Huuki (2017). Thinking beyond student resistances

deeply felt personal emotions. These are negotiated simultaneously with official curricula, practice school staff and curriculum, teacher educators' professional ambitions, students' professional ambitions and personal histories, peers, material surroundings, media, and so on. It follows that formal teacher education is not simply something done to student teachers within an institution but something they do to themselves as they negotiate with the various and sometimes conflicting elements of the assemblage. The lecture, then, is a transient cutout from this teacher education assemblage.

Each element in an assemblage can carry affects. Feminist new materialist theories have considered affect in Deleuzo-Guattarian terms as a "life force" and as a body's capacity to affect and be affected (Coleman and Ringrose 2013). Affect is not "a personal feeling" but a prepersonal intensity that is

felt before it is thought: it has visceral impact on the body before it gives subjective or emotive meaning...Affect is...different from emotion: it is an a-subjective bodily response to an encounter. Emotion comes later; a classifying or stratifying of affect (Hickey-Moody and Malins 2007, 9)

Affect, then, refers to life processes as a set of flows that circulate and pass between bodies and are difficult to capture (Blackman 2012,4). Some topics may carry affects, and these affects move us - "happen to us" - as we engage with those topics in teacher education. As affects move us, they are not "innocent"; the term "affective politics" (Ahmed 2004) characterises affects as significant political forces that work to produce particular alignments with some individuals and against others. Affects transmit historical patterns of social organization silently, gradually and seamlessly (Walkerdine and Jiminez 2012). Affects come to be transmitted and sedimented through relations of time and space and routines, practices, ways of relating and ways of holding and experiencing the body. Through repetition over time, these become settled patterns. In this way, each community produces certain forms of relating and organising and modes of being.

The concepts of assemblage and affect enable us to think of the described event not only in terms of human or other agency but also in terms of shifting flows of forces. In considering a lecture as an assemblage, we see it as a play of affectively charged forces within the collective, relational networks of multiple bodies, things, ideas and social formations, cutting across cultural and natural realms and producing bodily capacities of doing and feeling. 
Lanas \& Huuki (2017). Thinking beyond student resistances

\section{Post-human analysis: thinking with data}

The described event occurred during a didactics course for subject teachers at a university in Finland. As one of the course contributors, the second author (Tuija) was delivering a lecture on power relations in young peer cultures. After the lecture (which, according to Tuija's own interpretation and their comments had discomforted both student teachers and Tuija herself), she wrote a detailed description of what had happened in the lecture (summarised in the opening section). Over the following six months, we spent a number of sessions discussing and disentangling the "qualitative multiplicities" (Braidotti 2006) that rippled across the event.

Post-structural and post-human analysis is sometimes described as a process of "thinking with" theory or data (Jackson and Mazzei 2012). In rethinking the ontoepistemological assumptions within which educational research is commonly conducted, many post-structural and post-human scholars have shied away from such concepts as "data," "analyzing data" and "coding," arguing that these embody a positivist approach to science and fail to produce anything qualitatively new (see for example Denzin 2013; Jackson and Mazzei 2012; St. Pierre 2013). Putting Deleuze and Guattari's (1987) affective assemblage analysis to work, we were able to place elements of various qualities and features in the same analytical frame to explore power relations and bonds between the various elements of the assemblage.

Having isolated three different modalities — content, discourse and objects — we explored how they came together to cause discomfort and pain. Below, we create three assemblages, each of which explores a different modality and connects the lecture to the wider socio-material-discursive relations of teacher education. The first section (Discussing violence in children's peer cultures) focuses on the content and begins by illuminating the affects that for many aspiring educators inhere in the topic itself. This foregrounds how the affective content of the lecture is experienced as intensively personal, and how affects "jump" from past to present, causing anxiety for the teacher students as well as for Tuija. The second section (Teacher education as a discursive context) explores how teacher education that is largely instrumentalist and performative has produced certain discursive norms that determine what can be learned. The third section (Teacher education as material surroundings) explores how non-human objects and spatial elements of the material context come together to engender anxiety within the event. 
Lanas \& Huuki (2017). Thinking beyond student resistances

\section{Discussing violence in children's peer cultures}

The content of the lecture focused on normative cruelties (Ringrose and Renold 2010) in young people's peer cultures, giving several examples of situations in young people's every-day lives which, on the surface-level seem innocent but which pave the way for more explicit forms of violence, and maintain power hierarchies among and between genders. As we have discussed elsewhere, the topic of children and violence carries multiple affective charges (Holford, Renold and Huuki 2013; Huuki and Renold 2016). Discussing the topic with teacher students may engender a "goose bump effect" (Probyn 2004, 29-30), in which students may experience a strong affective reaction to the taught content. The topic may arouse personal and even painful feelings in many of those asked to engage with it. Everyone has been a child, involved in peer relationships and power plays; for many, the topic causes deep personal memories to resurface, evoking emotions and personal or collective experiences. Media and socially shared stories also tell of peer violence among children, connected to tragedies, deaths or traumas. Some are carers for children, and some have been teachers of children; in adults, the affective flows evoked by violence in children's peer cultures inform emotions such as helplessness, guilt, shame, weakness or hatred of weakness, as well as more positive feelings of recovery, companionship, security and empowerment. At the mention of "violence" and "children" in one sentence, then, multiple, shifting layers of affects instantly circle the lecture hall, resonating in different individuals in different ways.

Furthermore, as well as being personal and painful, the content of lecture was also unfacilitated by the students' existing knowledge and the dominant discourses. The topic of peer violence among young people is commonly discussed in terms of bullying - a canon so strong in Finland that it is a relatively familiar framework for future teachers. ${ }^{1}$ The concept of bullying makes the issue approachable by portraying children's peer violence as something that can be defined, addressed, located and prevented, and for which management strategies can be invented and implanted. However, the lecture did not discuss the issue in terms of bullying but in terms of the subtle forms of violence in children's unequal power relations before they become bullying-entangled in mutual friendship and relationality, teasing and seemingly innocent or random pranks or jokes,

\footnotetext{
${ }^{1}$ We refer here to research on bullying conducted largely in the field of developmental social psychology.
} 
emphasising that the line between bullying and not bullying is often fluid, and that such a distinction is not always viable. When framed this way, it becomes apparent that there are no simple management strategies that could be implanted.

This view of peer violence as a mundane, everyday phenomenon is not only quite new in the mainstream field of education but also counters powerful prevailing discursive representations of childhood and children. In the developmental literature, children and childhood are commonly romanticised as innocent, pure and authentic (Papadopoulos 2010) unless seen as dangerous, deviant or disturbed individuals. In relation to everyday peer violence, this alternate view positions children differently, reframing children and childhood and subverting notions of the "innocent other". Drawing on postcolonial theorizations (Hall, 1997; Said, 1978), when our "Other" is shaken, our self is also shaken. It follows that in asking students to rethink childhood, they must also rethink adulthood in relation to childhood, ultimately challenging their existing conceptualizations of what it means to be a teacher of children.

These forces brought a sense of uncertainty and insecurity to the lecture room that resonated in the students' conduct as well as in the Tuija's feelings. While it would be easy to frame this as student resistance, new feminist materialist and post-human approaches instead enable framing it as a discursive-material assemblage in which affective charges linking to participating individuals' knowledge of childhood and personal experiences of the past "jump" (Stewart 2007, 39) into the present across timespace domains. In the next section, these discursive affective charges are discussed in terms of the wider discursive force relations embedded in teacher education.

\section{Teacher education as a discursive context}

Any context in which an event occurs participates in creating the event itself. As a context, teacher education embodies histories, status positions, cultures and discourses that affect how issues come to be seen, felt and addressed, impacting what can be thought and said and enabling some subject positions while closing off others. In teacher education, there are few structures in place to identify, accept and work with difficult emotions and affective charges. Emotions tend to be seen as distinct from rationality, as forces that influence us from the outside (Zembylas and Fendler 2007) and as something to be "managed". Conversely, knowledge tends to be perceived as emotion-free and essentially painless, and in general, experiencing pain in connection with learning is considered 
Lanas \& Huuki (2017). Thinking beyond student resistances

unjustified (Wang 2005; 2008, 12). Instead, this provokes a sense of alarm and may be interpreted as a signal that something is wrong. As Tuija and the students were engaging with an emotionally charged topic, that engagement inherently challenged existing intuitive understandings of what was perceived as "right", appropriate and safe in the context.

Additionally, teacher education entails normative expectations of professionalism as "being ready", of knowledge as answers, and of teachers as the ones who must have those answers. Student teachers tend to imagine that they should learn what truths to teach and how to teach those truths truthfully (Taguchi 2007, 278-279; Phelan 2011), and they may feel that they have not learned enough if they are unable to apply their "learnings" directly. This context does not facilitate a grasp of knowledge that is open by nature; in the student comments after the lecture, the urge to "solve" by "doing something" surpassed the urge to "know" by "understanding more about". The students' question, "But what can we do about this?" was annoyed, worried and slightly panicked, echoing a common popular demand that "Teachers should (be able to) do something".

\section{Teacher education as material surroundings}

Like the discursive setting, the material setting of teacher education enables some subject positions and closes off others. The space itself, the place and the more-than-human bodies participate in the assemblage and work to mediate affects. Human and non-human relations affect and are affected by each other, producing all kinds of material effectscognitive capacities and desires, identities and the many "discourses" around learning, teaching and pedagogy. Regardless of whether a relation is human or non-human, these affects are qualitatively equivalent, producing capacities to act, to feel or to desire (Fox and Alldred 2013).

The lecture hall was a large, non-intimate space of a kind that is quite common in university settings, with the lecturer located at floor level and the 200-seat audience rising diagonally about 20 meters above. The chairs were non-movable, and the audience sat in rows, facing the lecturer. This positioned the lecturer at the centre; the audience had no scope to move, and anything that might be said by someone in the front rows had to be repeated to others by the lecturer. This setting invites a physically passive audience as non-moving, non-vital bodies. Audience members were also physically close to each other, their personal space invaded in a way familiar to students. A lecturer might well 
feel quite strongly the affect created by this mass of people, shoulder to shoulder, looking on in silence, and might find herself hiding behind the podium, as Tuija did. The more tense the room became, the more Tuija found herself clinging to her lecture notes, as if the entire lecture took place between her and her notes, contributing further to the separation between audience and her, and to the ensuing tension.

Clearly, the affordances of spaces, places and objects impact how we behave in situations we experience as challenging. As well as being personally painful and discursively unfacilitated, the lecture content also conflicted directly with the response invited from participants by the material environment. The non-intimate material surroundings conflicted with the personally experienced, emotional and intimate topic. The rows of benches, the podium, and the lecture notes established a familiar context - a map even - that led both students and lecturer away from intimacy, emotions and new encounters, in which new knowledge might have been produced.

\section{New landscapes: engaging with sensitive issues in teacher education}

In this analysis of a discomforting event, we have, throughout the paper, discussed the contribution of feminist new materialist and post-human approaches in highlighting the affects, materialities and discourses that together produce what comes to be known as teacher education. Through this post-human lens we can see how the pain of such an event is not produced solely by the emotional topic, or the pedagogy, or the material surroundings, or the student expectations, or the contemporary teacher education discourses; instead, that pain is produced when all these come together as the constitutive forces of normative teacher education.

Affect disrupts expectations of teacher-sovereignty. In the event analysed here, the speed and unpredictability with which affect is transmitted bears little resemblance to the ordered, individualised transfer of knowledge constructed by traditional conceptions of teacher-centred pedagogy. In its capacity to move beyond the boundary of the skin, affect punctures fantasies of the individualised and self-contained human subject (Blackman 2012), challenging human-centred conceptions of pedagogy. We argue that the "solution" is not to govern, prevent or indeed resolve such confluences but to work with the ensuing affect.

We would like to conclude by outlining four implications of working with affect for teacher education. Firstly, teacher educators could purposefully plan their teaching so 
Lanas \& Huuki (2017). Thinking beyond student resistances

that discomforting events are not perceived as something hindering learning (which makes them something to prevent), but as the places for learning (which makes them something to support), especially when dealing with sensitive topics. This means accepting that deep discomfort, difficult emotions and surprises are a significant part of the shared learning process, and joint learning could even be organised around such events. Listening to affect may be a useful skill in students' future occupation as teachers. Secondly, teacher educators could purposefully steer away from discussing events in terms of student resistance. Such perspective unnecessarily simplifies issues and places the problem within the students. Instead, attention should be paid to wider field of power relations by asking what else is taking place: could the students be resisting not the content, but the emotions for which there is no safe space within teacher education? Or, could the apparent "resistance" be more accurately described as students struggling to make sense of a new content in a discursive framework in which it does not directly fit?

Third, the material surroundings steer what happens within them. Since some topics in teacher education are intimate and emotional, the material surrounding could be planned so that they enable engaging with such topics, and the teacher educators could help students in analysing the material settings.

As a fourth implication, the thrust of this paper is in arguing that as teacher education is an affective context, all emotions are an essential part of it. A teacher educator engaging with sensitive topics may be bound to experience a sense of guilt, shame or even a sense of failure when unprecedented discomfort emerges. However, even these are affective responses within a specific environment, signalling that it would somehow be the teacher educators' task to prevent discomfort at the face of sensitive topics. As teacher educators committed to social justice and wellbeing, our primary task is not to prevent discomfort aroused by sensitive topics but to work with it. 
Lanas \& Huuki (2017). Thinking beyond student resistances

References

Ahmed, S. 2004. The Cultural Politics of Emotion. Edinburgh: Edinburgh University Press.

Alaimo, S., and S. Hekman, eds. 2008. Material Feminisms. Bloomington: Indiana University Press.

Aveling, N. 2002. "Student teachers' resistance to exploring racism: Reflections on 'doing' border pedagogy.” Asia-Pacific Journal of Teacher Education 30 (2): 119130. doi:10.1080/13598660220135630.

Aveling, N. 2006. “'Hacking at our very roots': Rearticulating white racial identity within the context of teacher education." Race, Ethnicity \& Education 9 (3): 261-274. doi:10.1080/13613320600807634.

Barad, K. 2007. Meeting the Universe Halfway: Quantum Physics and the Entanglement of Matter and Meaning. Durham: Duke University Press.

Barcan, R. 2002. "Problems without solutions: Teaching theory and the politics of hope." Continuum: Journal of Media \& Cultural Studies 16 (3): 343-356. doi:10.1080/1030431022000018708.

Blackman, L. 2012. Immaterial Bodies. Affect, Embodiment, Mediation. Los Angeles: Sage.

Blaise, M., and J. Elsden-Clifton. 2007. "Intervening or ignoring: Learning about teaching in new times." Asia-Pacific Journal of Teacher Education 35 (4): 387-407. doi:10.1080/13598660701611404.

Braidotti, R. 2006. Transpositions: Nomadic Ethics. Cambridge: Polity Press.

Britzman, D. P. 1998. Lost Subjects, Contested Objects: Toward a Psychoanalytic Inquiry of Learning. Albany: State University of New York Press.

Bronkhorst, L. H., B. Koster, P. C. Meijer, N. Woldman, and J. D. Vermunt. 2014. “Exploring student teachers' resistance to teacher education pedagogies." Teaching \& Teacher Education 40: 73-82. doi:10.1016/j.tate.2014.02.001.

Bryant, J., and A. Bates. 2010. "The power of student resistance in action research: Teacher educators respond to classroom challenges." Educational Action Research 18 (3): 305-318. doi:10.1080/09650792.2010.499742. 
Lanas \& Huuki (2017). Thinking beyond student resistances

Cochran-Smith, M. 2003. "Learning and unlearning: The education of teacher educators." Teaching and Teacher Education 19(1):5-28. doi:10.1016/S0742-051X(02)000914.

Coleman, B., and J. Ringrose, eds. 2013. Deleuze and Research Methodologies Edinburgh: Edinburgh University Press.

Deleuze, G., and F. Guattari. 1987. A Thousand Plateaus: Capitalism and Schizophrenia. Minneapolis: University of Minnesota Press.

Denzin, N. K. 2013. “The Death of Data?” Cultural Studies $\leftrightarrow$ Critical Methodologies 13 (4): $353-356$.

Evans-Winters, V., and P. Twyman Hoff. 2011. "The aesthetics of white racism in preservice teacher education: A critical race theory perspective." Race, Ethnicity \& Education 14 (4): 461-479. doi:10.1080/13613324.2010.548376.

Fox, N., and P. Alldred. 2013. "The sexuality-assemblage: Desire, affect, antihumanism." Sociological Review 61 (4): 766-789.

Furlong, C. 2013. "The teacher I wish to be: Exploring the influence of life histories on student teacher idealised identities." European Journal of Teacher Education 36 (1): 68-83. doi:10.1080/02619768.2012.678486.

Green, B., and J. Reid. 2008. "Method(s) in our madness? Poststructuralism, pedagogy and teacher education. In Critical readings in teacher education: Provoking absences, edited by A. M. Phelan and J. Sumsion, 17-31. Rotterdam: Sense Publishers.

Grosz, E. 2011. Becoming Undone. Durham and London: Duke University Press.

Guattari, F. 1995/2005. Chaosmosis: An Ethico-aesthetic Paradigm. Sydney: Power Publications.

Hall, S. 1997. Representation: Cultural Representations and Signifying Practices. London: Sage.

Hickey-Moody, A., and P. Malins, eds. 2007. Deleuzian Encounters: Studies in Contemporary Social Issues. New York: Palgrave Macmillan. 
Lanas \& Huuki (2017). Thinking beyond student resistances

Holloway, S. M., and P. A. Gouthro. 2011. "Teaching resistant novice educators to be critically reflective." Discourse: Studies in the Cultural Politics of Education 32 (1): 29-41. doi:10.1080/01596306.2011.537069.

Holford, N., E. Renold, and T. Huuki. 2013. "What (else) can a kiss do? Theorizing the power plays in young children's sexual cultures." Sexualities 16 (5/6): 710-729.

Huuki, T., and E. Renold 2016. "Crush: Mapping historical, material and affective force relations in young children's hetero-sexual playground play." Discourse: Studies in the Cultural Politics of Education 37 (5): 754-769.

Jackson, A. Y., and L. A. Mazzei. 2012. Thinking with Theory in Qualitative Research: Viewing Data Across Multiple Perspectives. London: Routledge.

Lanas, M. 2014. "Failing intercultural education? 'Thoughtfulness' in intercultural education for student teachers." European Journal of Teacher Education 37 (2): $171-182$.

Lanas, M. 2015. “"This has more to do with who I am than with my skills'—student teacher subjectification in Finnish teacher education." Teaching and Teacher Education 47: 22-29.

Lenz Taguchi, H.2007. "Deconstructing and transgressing the Theory-Practice dichotomy in early childhood education." Educational Philosophy \& Theory 39 (3): 275-290. doi:10.1111/j.1469-5812.2007.00324.x.

Manning, E. 2013. Always More Than One: Individuation's Dance. Durham and London: Duke University Press.

Niccolini, A. 2016. “Animate affects: Censorship, reckless pedagogies, and beautiful feelings." Gender and Education 28 (2): 230-249.

Papadopoulos, L. 2010. Sexualisation of Young People Review. London: Home Office.

Phelan, A. M. 2011. "Towards a complicated conversation: Teacher education and the curriculum turn." Pedagogy, Culture \& Society 19 (2): 207-220. doi:10.1080/14681366.2011.582257.

Phillips, D. K. 2010. “On transitional space, unresolved conflicts, and an uncertain teacher education." Teachers \& Teaching 16 (5): 633-644. doi:10.1080/13540602.2010.507970. 
Lanas \& Huuki (2017). Thinking beyond student resistances

Probyn, E. 2004. "Teaching bodies: Affects in the classroom." Body \& Society 10 (4): $21-43$.

Ringrose, J. and E. Renold, E. 2010. Normative cruelties and gender deviants: The performative effects of bully discourses for girls and boys in school. British Educational Research Journal 36 (4): 573-596.

Rots, I., G. Kelchtermans, and A. Aelterman. 2012. Learning (not) to become a teacher: A qualitative analysis of the job entrance issue. Teaching and Teacher Education 28 (1): 1-10. doi:10.1016/j.tate.2011.08.008.

Said, E. W. 1978. Orientalism. London: Routledge \& Kegan Paul.

Segall, A. 2008. "Why teaching critical social theory as theory might not be enough." In Unsettling beliefs: Teaching Theory to Teachers, edited by R. J. Helfenbein and J. Diem, 15-29. Charlotte, NC: Information Age Publishing.

Stewart, K. 2007. Ordinary Affects. Durham: Duke University Press.

St. Pierre, E. A. 2013. "The Appearance of Data." Cultural Studies/Critical Methodologies 13 (4): 223-227. doi: 10.1177/1532708613487862.

Strom, K. 2015. "Teaching as Assemblage: Negotiating Learning and Practice in the First Year of Teaching." Journal of Teacher Education 66 (4): 321-333.

Sumara, D., B. Davis, and T. Iftody. 2008. "101 ways to say 'Normal'." In Critical Readings in Teacher Education: Provoking Absences, edited by A. M. Phelan and J. Sumsion, 155-172. Rotterdam: Sense Publishers.

Titus, J. J. 2000. "Engaging student resistance to feminism: 'How is this stuff going to make us better teachers?" Gender \& Education 12 (1): 21-37.

Wang, H. 2005. “Aporias, responsibility, and the im/possibility of teaching multicultural education." Educational Theory 55 (1): 45-60. doi:10.1111/j.00132004.2005.00004.x.

Wang, H. 2008. “'Red eyes': Engaging emotions in multicultural education." Multicultural Perspectives 10 (1): 10-16. doi:10.1080/15210960701869330.

Walkerdine, V., and L. Jiminez. 2012. Gender, Work and Community after Deindustrialisation. A Psychosocial Approach to Affect. Basingstoke: Palgrave Macmillan. 
Lanas \& Huuki (2017). Thinking beyond student resistances

Williams, D. G., and V. Evans-Winters. 2005. "The burden of teaching teachers: Memoirs of race discourse in teacher education." Urban Review 37 (3): 201-219. doi:10.1007/s11256-005-0009-z.

Youdell, D., and F. Armstrong. 2011. "A politics beyond subjects: The affective choreographies and smooth spaces of schooling." Emotion, Space and Society 4: $144-150$.

Zembylas, M. 2010. "Racialization/ethnicization of school emotional spaces: The politics of resentment." Race, Ethnicity \& Education 13 (2): 253-270. doi:10.1080/13613321003751528.

Zembylas, M., and L. Fendler. 2007. "Reframing emotion in education through lenses of parrhesia and care of the self." Studies in Philosophy \& Education 26 (4): 319-333. doi:10.1007/s11217-007-9042-6. 